\title{
The Metabolic Syndrome and Cardiovascular Diseases: An Update of Medical Treatment
}

\author{
Markolf Hanefeld ${ }^{1}$, Frank Pistrosch ${ }^{1}$, Jan Schulze ${ }^{2}$ and Ulrike Rothe S $^{3^{*}}$ \\ ${ }^{1}$ GWT-TUD GmbH, Study center Prof. Hanefeld, Dresden, Germany \\ ${ }^{2}$ Saxonian Chamber of Physicians, Dresden, Germany \\ ${ }^{3}$ Health Sciences/Public Health, Faculty of Medicine, TU Dresden, Germany
}

*Corresponding author: Ulrike Rothe, Health Sciences/Public Health, Faculty of Medicine Carl Gustav Carus, Technische Universität Dresden, Fetscherstrabe 74, D-01307 Dresden, Germany, Tel: 493513177 23; Fax: 493513177 233; E-mail: ulrike.rothe@tu-dresden.de

Received date: July 23, 2014; Accepted date: August 27, 2014; Published date: August 30, 2014

Copyright: (c) 2014 Hanefeld M, et al. This is an open-access article distributed under the terms of the Creative Co mmons Attribution License, which permits unrestricted use, distribution, and reproduction in any medium, provided the original author and source are credited

\begin{abstract}
The metabolic syndrome represents a cluster of closely connected premorbid risk factors or diseases with visceral obesity, prediabetes or type 2 diabetes, hypertension and low dyslipidemia as established traits affecting about $20 \%$ of adults in developed countries. This syndrome develops on a common soil with overnutrition, low physical activity and psychosocial stress as major components. Common comorbidities are fatty liver, sleep apnoe and gout with cardiovascular complications, nephropathy and type 2 diabetes as 'endstage' diseases. The term metabolic vascular syndrome was proposed to signal premorbid cardiovascular state and increased cardiovascular morbidity. Thus, a rational diagnostic is needed to elucidate the complex cluster of diseases as basis for an integrated therapy. There is a clear priority for life style intervention however most diseases of the metabolic syndrome need medical treatment. Medical treatment of single traits has to take into account possible pleiotropic or adverse effects on the other traits. Here we present the pros and cons of major medical interventions in type 2 diabetes, hypertension, dyslipidemia and hypercoagulation in the context with the metabolic syndrome.
\end{abstract}

Keywords: Actigraphy; Sleep disorders; Attention deficit and hyperactivity disorder; Pediatric population

\section{Introduction and Definition}

Pre-diabetes or type 2 diabetes, hypertension and dyslipidemia are core components (Table1). Moreover, clinical manifestations include increased risk of non-alcoholic fatty liver (NAFLD), gout, sleep apnoe, depression cancer and sexual dysfunction. It is mainly caused by overeating together with low level of physical and socio-cultural activity in societies with a rapid transition to western life style and aging populations. The relationship between type 2 diabetes, hypertension and gout was first described by Maranon and Kylin [2] J. Vague in 1956 linked visceral (masculine) obesity to glucose intolerance and dyslipidemia what was later described as 'plurimetabolic syndrome' by G. Crepaldi [3,4]. In 1981 we gave a first definition of the metabolic syndrome: "By this term, we understand the simultaneous occurrence of obesity, hyper- and dyslipoproteinemia, maturity onset diabetes (type 2), gout, and hypertension, associated with an elevated incidence of atherosclerotic vascular diseases, fatty liver, and gallstones in overfed, physically inactive and genetically predisposed people" [5]. The rise of the metabolic syndrome into one of the most cited syndromes however started when G. Reaven presented insulin resistance as the common soil for type 2 diabetes, hypertension and dyslipidemia in his 1988 Banting Lecture and called it syndrome $\mathrm{X}$, more or less as synonym for insulin resistance syndrome [6,7].With a rapid change in life-style around the globe a pandemic of the diseases of the metabolic syndrome was observed affecting 20 to $50 \%$ of the adult population [8]. A first world-wide definition was published by the International Diabetes Federation (IDF) in 2006 [9] (Table 1) with the American Heart Association (AHA) /National Cholesterol Education Program III (NCEPIII) criteria as one of the most frequently used competitor which better meets cardiovascular risk [10]. To overcome confusion by too many competing definitions a unifying definition was developed in 2009 (Table 1) [11].

\begin{tabular}{|c|c|c|c|}
\hline & AHA/ NCEP III & IDF & Consensus statement \\
\hline Central obesity/waist & $\begin{array}{l}>102 \mathrm{~cm}(\mathrm{~m}) \\
>88 \mathrm{~cm}(\mathrm{w})\end{array}$ & $\begin{array}{l}\geq 94 \mathrm{~cm}(\mathrm{~m}, \text { European }) \\
\geq 90 \mathrm{~cm}(\mathrm{~m}, \text { Asian }) \\
\geq 80 \mathrm{~cm}(\mathrm{w})\end{array}$ & $\begin{array}{l}\text { Population and country specific } \\
\text { increased waist circumference }\end{array}$ \\
\hline Blood pressure $(\mathrm{mmHg})$ & $\geq 130 / 85$ or treated for hypertension & $\geq 130 / 85$ or treated for hypertension & $\geq 130 / 85$ or treated for hypertension \\
\hline Triglycerides (mmol/l) & $\geq 1.7$ & $\geq 1.7$ or treatment & $\geq 1.7$ or treatment \\
\hline HDL-cholesterol (mmol/l) & $<1.03(\mathrm{~m}),<1.29(\mathrm{w})$ & $<1.03(\mathrm{~m}),<1.29(\mathrm{w})$ & $<1.03(\mathrm{~m}),<1.29(\mathrm{w})$ or treatment \\
\hline
\end{tabular}




\begin{tabular}{|l|l|l|l|}
\hline & & or treatment & \\
\hline Fasting plasma glucose $(\mathbf{m m o l} / \mathbf{l})$ & $\geq 5.6$ & $\geq 5.6$ or diagnosed with diabetes mellitus & $\begin{array}{l}\geq 5.6 \text { or drug treatment for elevated } \\
\text { glucose }\end{array}$ \\
\hline
\end{tabular}

Table 1: Definition of the metabolic syndrome, AHA: American Heart Association, NCEP: National Cholesterol Education Program, IDF: International Diabetes Federation

Here we consider the metabolic syndrome as a cluster of premorbid risk factors and/or developed diseases with a common soil in malnutrition, lifestyle factors, socio-economic conditions and genetic predisposition. These conditions not only affect diseases of the metabolic syndrome but also interact with classical risk factors such as smoking and low-densitiy lipoprotein (LDL)-cholesterol. Recently increased inflammatory activity and endothelial dysfunction could be identified as components of the metabolic syndrome [12]. Therefore the term metabolic vascular syndrome was proposed to signal premorbid cardiovascular state and increased cardiovascular morbidity [13]. Type 2 diabetes and cardiovascular diseases thus may be considered as 'end stage' sickness of the metabolic syndrome [14]. With this in mind the metabolic syndrome provides an integrated approach for rational diagnostic and prevention of a broad spectrum of intricately connected diseases.

\section{Pathophysiology}

The metabolic syndrome rose to increased clinical consideration and scrutiny together with the worldwide epidemic of obesity and diabetes. However the pathophysiological mechanisms leading to this cluster of metabolic diseases and eventually cardiovascular complications are not completely understood [15]. Although insulin resistance is a core abnormality of individuals with metabolic syndrome [16], there is no sufficient evidence for a causal link between the two [17]. The most promising hypothesis for a single causal link between the development of the different traits of the metabolic syndrome and atherosclerosis is chronic low grade inflammation, particularly in dysfunctional adipose tissue [18]. The onset of abdominal obesity is central to the alteration of normal adipose tissue function with decreased glucose uptake, increased storage of fat as well as increased release of non esterified fatty acids (FFA) into the circulation. In obesity adipose tissue is infiltrated by macrophages which influence its cytokine production. There is an increased release of interleukin 6, tumor necrosis factor a (TNFa), monocyte chemo attractant protein 1 (MCP1) or C-reactive protein (CRP) whereas release of adiponectine is decreased. Whether the inflammatory response of the visceral adipose tissue is primarily induced by intracellular fat accumulation or by infiltration of activated macrophages is still a matter of debate [19]. Thus, the impact of changes in visceral adipose tissue can be summarized as a state of systemic lipotoxicity and low grade inflammation. Inflammatory cytokines are involved in the induction of endothelial dysfunction and insulin resistance [20]. Furthermore the insulin resistant state of obesity is characterised by increased plasma levels of free fatty acids that have cardiotoxic effects and impair the production of endothelial vasodilators $[2,22]$.

In addition to these systemic effects of visceral obesity there is a local impairment of cardiac and vascular function by dysfunctional perivascular adipose tissue (PVAT) [23]. Under normal conditions PVAT produces different cytokines and hormones which contribute to vascular relaxation. In the obese state PVAT mass, like visceral adipose mass is increased and its anticontractile effects are diminished. Therefore PVAT in obesity may contribute to endothelial function and hence atherosclerosis and plays a key role in the development of vascular insulin resistance $[24,25]$.

A common hypothesis describes metabolic susceptibility as central factor for the development of the metabolic syndrome. This metabolic susceptibility is determined by polygenic variability of individuals [26] but also gene-environment interactions $[20,27]$. Once a sedentary lifestyle with decreased physical activity and high caloric intake leads to the acquisition of body fat and development of overweight and obesity, a susceptible individual is at high risk to develop the metabolic syndrome and cardiovascular consequences. Genome wide association studies have identified a lot of potential genetic variants that may contribute to development of metabolic syndrome, however, the complexity of its different single traits with their own genetic determinants is a major challenge for the genetic studies [28]. Despite this complex pathophysiology as soil for the metabolic syndrome and associated diseases, we also have to keep in mind the strong impact of lifestyle and environment which lead to epigenetic regulation such as the methylation of desoxyribonucleinacids (DNA) nucleotides and the modification of histone proteins surrounding the DNA double helix. These mechanisms as key regulators of gene expression can explain inter-individual variation of phenotypes [29]. Recent studies demonstrated a close relationship between intrauterine growth retardation and metabolic disease in adulthood. Low birth weight has also been associated with hypertension and susceptibility to cardiovascular diseases [30]. In addition to heritable regulation of the epigenome, there is also evidence of lifestyle-related modification of genes in adulthood [31].

A completely new area of metabolic and genetic research is the so called intestinal microbiome. Intestinal bacteria can influence immunological and inflammatory processes as well as gene expression within the intestinal wall. Animal studies demonstrated that gut microbiota can transfer metabolic diseases between individuals [32].

As a conclusion, there are several genetic and environmental factors which contribute to the development of both metabolic disorders which are summarized as metabolic syndrome and cardiovascular disease. It is conceivable that metabolic and cardiovascular disorders develop in parallel and and eventually interact in a vicious cycle. Therefore, the term metabolic vascular syndrome might be the most comprehensive description of this cluster of diseases [13].

\section{Comorbidities and related cardiovascular risk factors}

In the majority of cases which meet the criteria of the unifying definition or NCEPIII criteria we find comorbidities and cardiovascular risk factors which are summarized in Table 2. Among these broad spectrum NAFLD and albuminuria have been identified as major risk factors for both type 2 diabetes and cardiovascular disease 
[33,34]. Therefore abdominal palpitation and ultrasound measurement of the liver and measurement of liver enzymes is good clinical practice in cases with metabolic vascular syndrome. The same applies for measurement of albumin to creatinine ratio in urine. However there don't exist any specific complication or comorbidity. The majority of related risk factors can be linked to visceral obesity or ectopic fat but also can be found in single diseases such as hypertension or dyslipidemia. For example hypertriglyceridemia is associated with an increase in highly atherogenic small dense LDL. Risk scores (e.g. Prospective cardiovascular Muenster [PROCAM]Score) are useful to support physician's decision making [13].

\begin{tabular}{|c|}
\hline Fatty liver (NAFLD) \\
\hline Hyperuricaemia/gout \\
\hline Hypercoagulation/impaired fibrinolysis \\
\hline Endothelial dysfunction, insulin resistance \\
\hline Osteoporosis \\
\hline Late hypogonadism \\
\hline Sleep apnoe \\
\hline
\end{tabular}

Table 2: Frequent comorbidities and associated risk factors of the metabolic syndrome

\section{Consequences for an integrated prevention of 'end-stage diseases'}

\section{Lifestyle intervention}

From a clinical viewpoint type 2 diabetes and cardiovascular disease such as coronary heart disease, cerebrovascular disease and peripheral arterial disease can be considered as end-stage diseases developing on the complex prodiabetic and proatherogenic soil of the metabolic vascular syndrome. The rational of this concept is essential for lifestyle intervention and improving socio-economic conditions, avoiding stress exposure and as guide for regulation of food production and trade. This is a challenge for the whole society.

So far best evidence for modifiable risk factors for prevention of the metabolic vascular syndrome is available for changes in nutrition and increased physical activity to reduce overweight and insulin resistance. There exists now a bulk of evidence that with effective lifestyle intervention the incidence of type 2 diabetes can be reduced by about $50 \%[35,36]$. Lifestyle intervention trials with similar integrated approach including psychosomatic treatment tools - have also successfully been performed for the prevention, primary and secondary, of cardiovascular diseases [37-39].

\section{Medical intervention balance - antihypertensive drugs}

Subjects with the metabolic vascular syndrome are at high risk for development of cardiovascular events according to the Systematic Coronary Risk Evaluation (SCORE) model even if they have grade 1 hypertension [40]. International guidelines recommend systolic blood pressure control to a level $<140 \mathrm{mmHg}$ and diastolic blood pressure control to $<90 \mathrm{mmHg}$ depending on age, individual risk and comorbidities with focus on kidney disease [13,41]. To reach this treatment goal 4 classes of antihypertensive drugs are recommended as first line treatment by the European Society of Hypertension/
European Society of Cardiology (ESH/ESC) guidelines: angiotensin converting enzyme (ACE) inhibitors/angiotensin II receptor (ARB) blockers, calcium channel blockers, beta blockers and diuretics. While blood pressure lowering effect and cardiovascular benefit is similar for these 4 classes of antihypertensive agents there are some differences in metabolic effects which should be considered in patients with the metabolic vascular syndrome. Beta blocker can increase body weight and - in combination with diuretics - the incidence of type 2 diabetes $[13,42,43]$ however, newer beta blocker e.g. nebivolol and carvedilol did not affect insulin sensitivity and should therefore be preferred in patients with the metabolic vascular syndrome [44,45]. The ACCOMPLISH (Avoiding cardiovascular events in combination therapy in patients living with systolic hypertension) trial demonstrated a higher rate of cardiovascular events in patients receiving a combination therapy of a thiazide diuretic and an ACE inhibitor compared to patients with an ACE inhibitor/calcium channel blocker [46]. So far other randomized trials confirmed this superiority of calcium channel blocker over a diuretic treatment [41]. The use of thiazide diuretics can induce hypokalemia which may worsen glucose tolerance and provoke cardiac arrhythmias [47]. Due to their unfavourable metabolic effects beta blocker and diuretics should only be considered as additional blood pressure lowering drugs in metabolic syndrome in particular if free of vascular disease. If thiazide diuretics are used the addition of a potassium sparing diuretic agents could reduce the risk of hypokalemia [48].

ACE-inhibitor or ARB and calcium channel blocker should be preferred for the treatment of hypertension in patients with the metabolic vascular syndrome because they have no negative effect on insulin sensitivity or body weight. ACE-inhibitors/ARB are most effective in reducing proteinuria and preventing the progression of diabetic nephropathy whereas calcium channel blocker are the best choice for the prevention of stroke $[49,50]$. There is no evidence of an additional benefit of the newer ARB compared to ACE -inhibitors in patients with the metabolic vascular syndrome.

In the ONTARGET (Ongoing telmisartan alone and in combination with ramipril global endpoint) trial ARB telmisartan was associated with a significantly higher incidence of diabetes while no effect on primary objectives - major cardiovascular events was achieved [51]. In the HOPE (Heart outcomes prevention evaluation) study however with ACE inhibitor ramipril fewer patients were diagnosed with diabetes at the end of the study as in the placebo group 52. This could not be confirmed in the DREAM (Diabetes reduction assessment with ramipril and rosiglitazone medication) trial in people with impaired glucose tolerance where ramipril had no effect on the incidence of diabetes as a primary objective [53]. The same applies for ARB valsartan in the NAVIGATOR (Nateglinid and valsartan in impaired glucose tolerance outcomes research) trial - a prospective primary prevention study with cardiovascular complications as primary objective and diabetes as secondary objective [54].

To achieve blood pressure goals most patients need a combination therapy of 2 or more antihypertensive drugs. As recently recommended by the ESH/ESC Guidelines the initiation of a combination therapy instead of a monotherapy should be considered in patients with $>160 \mathrm{mmHg}$ systolic and/or $>100 \mathrm{mmHg}$ diastolic blood pressure. With combinations a prompter response in a larger number of patients to reach target blood pressure and a higher adherence of patients to the therapy was achieved [41]. Preferred drug combinations for initial treatment are that between ACE-inhibitor or $\mathrm{ARB}$ and calcium channel blocker whereas a combination of beta 
blocker and thiazide diuretic is not recommended as initial treatment for patients with the metabolic vascular syndrome [42].

In conclusion national and international guidelines recommend in patients with the metabolic vascular syndrome an individualized approach with age, comorbidities and presence or absence of end stage diseases as guide to decision.

\section{Antidiabetic drugs}

Evidence with antidiabetic drugs for the prevention of type 2 diabetes in people with abnormal glucose tolerance is available only for metformin [55], acarbose [56] and thiazolidinediones [57-59].

Metformin has consistent evidence to prevent progression of impaired glucose tolerance (IGT)/impaired fasting glucose (IFG) to type 2 diabetes. In the DPP Diabetes prevention program) sStudy the reduction in incidence of diabetes was $31 \%$ vs. $58 \%$ with lifestyle intervention alone [55]. The reduction of newly diagnosed diabetes in the STOP NIDDM (Study to prevent non-insulin-dependent diabetes mellitus) trial with a glucosidase inhibitor acarbose was in the same range if the same diagnostic criteria were used as in the DPP [56]. Despite glitazones were very effective to reduce incidence of newly diagnosed diabetes and had pleiotropic effects on blood pressure, biomarkers of inflammation and endothelial dysfunction [60-62] they cannot be recommended because of serious adverse effects such as edema, congestive heart failure and bone fractures for primary prevention of diseases of the metabolic vascular syndrome [63]. Orlistat, a weight reducing intestinal lipase inhibitor reduced incidence of diabetes in obese subjects with abnormal glucose tolerance by $~ 31 \%$ [64]. Metformin in addition had beneficial effects on weight and minor effects on blood lipids, but did not affect blood pressure in the DPP 64 and BIGPRO (Treatment with metformin of non-diabetic men with hypertension, hypertriglyceridaemia and central fat distribution) trial [66]. However, none of the primary prevention trials with metformin has shown an effect on major cardiovascular events, even in the long term follow-up after termination of the studies [65]. Acarbose so far is the only antidiabetic drug with a significant pleiotropic effect on elevated blood pressure [67]. It significantly reduced body weight, postprandial hyperinsulinemia, biomarkers of inflammation and hypertriglyceridemia $[68,69]$. Predefined cardiovascular events were secondary objectives in the STOP-NIDDM trial. In this trial a significant reduction in the incidence of myocardial infarction and of overall predefined cardiovascular events was registered [67]. Furthermore, 36\% less newly diagnosed cases of hypertension were observed. Of notice stable IGT or remission to NGT (normal glucose tolerance) was associated with a lower incidence of hypertension compared to progresses to type 2 diabetes [69]. In subjects with metabolic vascular syndrome the number needed to treat to prevent one case of diabetes was 5.8 versus $\sim 16.5$ in people without diabetes 71 (Figure 1). Intervention with basal insulin glargine in prediabetic subjects was evaluated in the ORIGIN (Outcome reduction with initial glargine intervention) trial. Reduction of newly diagnosed diabetes after 3 months stop of insulin treatment was $20 \%$. There was however no effect on major cardiovascular events achieved [72]. In conclusion, except for acarbose no evidence is available for glucose lowering treatment in subjects with prediabetes to prevent cardiovascular end stage diseases.
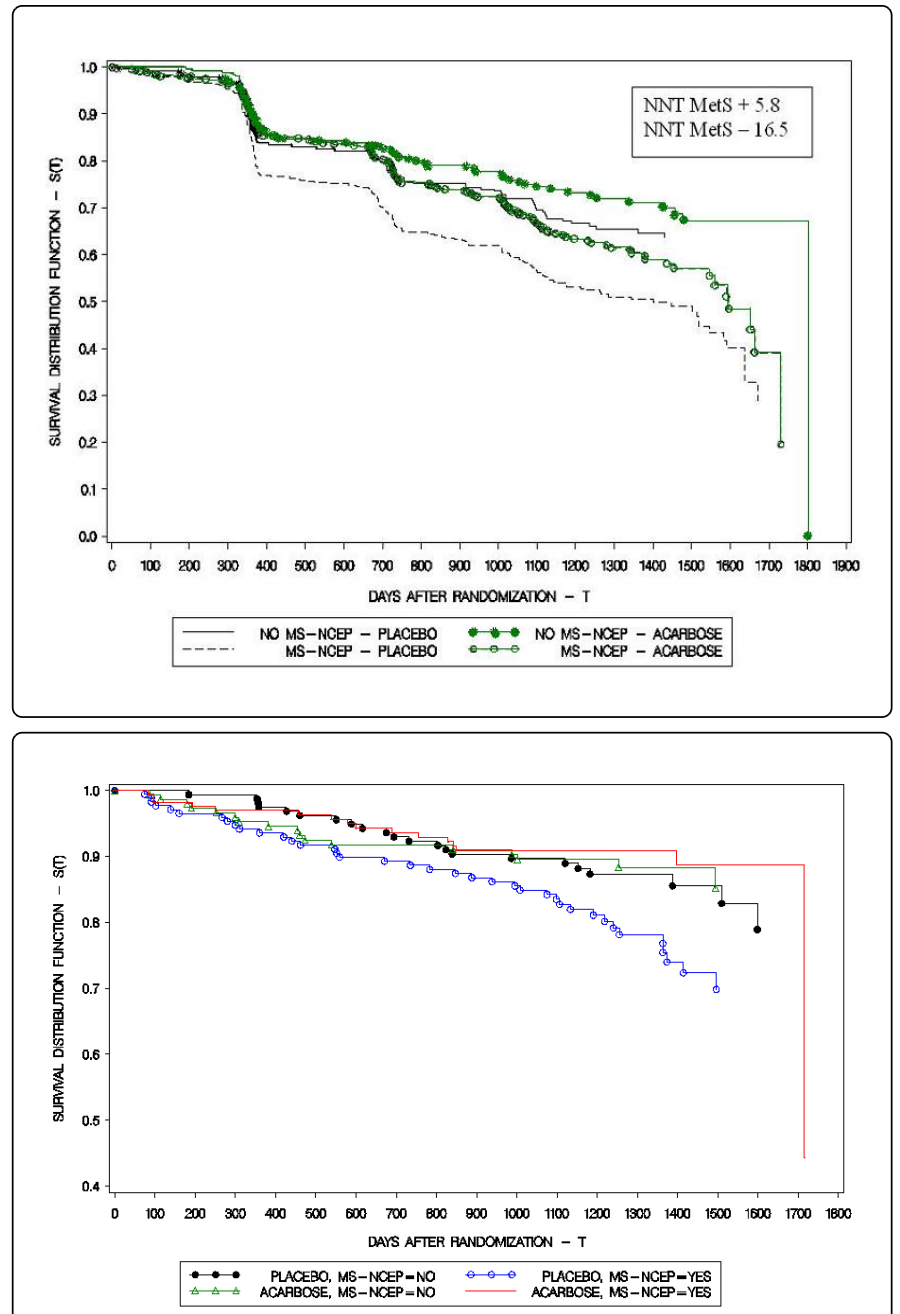

Figure 1: Impact of metabolic syndrome status on incidence of type 2 diabetes (A) and incidence of hypertension (B), data from the STOP NIDDM trial

\section{Lipid lowering drugs}

Dyslipidemia with hypertriglyceridemia and low high density lipoprotein (HDL) is in the majority of cases associated with an increase in small dense LDL, a lipoprotein subfraction with high atherogenic potential which is intricately connected with insulin resistance and low grade inflammation (Figure 2) [73]. This lipid triad together with high cardiovascular risk provides a rational pathophysiological basis for the use of statins as first line drug. Statins have a grade I evidence for primary $[74,75]$ and secondary $[76,77]$ prevention of cardiovascular disease. In the case of dyslipidemia with hypertriglyceridemia/low HDL they can be used in combination with fibrates. In the ACCORD (Action to Control Cardiovascular Risk in Diabetes) trial [78] and FIELD (Fenofibrate Intervention and Event Lowering in Diabetes) [79] in patients with hypertriglyceridemia fenofibrate had an additional beneficial effect on cardiovascular outcome when used in combination with statins. As shown in a metaanalysis of data from 170000 participants with intensive statin treatment reduction of cardiovascular events was mainly due to LDLcholesterol lowering efficacy [80]. However in the JUPITER 
(Justification for the use of statin in prevention: an intervention trial evaluating rosuvastatin) study in patients with elevated high sensitive $\mathrm{C}$-reactive protein (hSCRP) but LDL-cholesterol in the normal range rosuvastatin, one of the strong statins, reduced major cardiovascular events versus placebo [81]. Beneficial effects on the lipid triad in patients with the metabolic vascular syndrome have been documented for atorvastatin and rosuvastatin $[8,83]$. In long term studies, however, statins increased the risk of newly diagnosed diabetes [83]. This is far outweighted by the cardiovascular benefit. In a metaanalysis intensive dose statin therapy had a number needed to harm for one case of new onset diabetes of 498 versus a number needed to prevent one case of major cardiovascular events of 155 per year [84]. In addition statin treatment has a small but significant beneficial effect on blood pressure [85].

Fibrates have been shown to reduce cardiovascular events in patients with the metabolic vascular syndrome and type 2 diabetes [78,79]. The Helsinki Heart Study (HHS) and VAHIT (Veterans Affairs High-Density Lipoprotein Cholesterol Intervention Trial) study have demonstrated a significant reduction of cardiovascular events in patients with dyslipidemia and metabolic vascular syndrome treated with gemfibrozil versus placebo [86-88]. Gemfibrozil, however, is contraindicated for combination with statins because of high rates of myopathies and increased risk of rhabdomyolysis [89]. Low HDL is an established trait of the metabolic syndrome in all definitions (Table 1). However the concept to increase HDL-cholesterol to protect the vessel wall was not supported by recently published trials with nicotinic acid [90] and cholesteryl ester transfer protein (CETP) inhibitors [91,92] showing increased rates of serious adverse events but no benefit for primary objectives. Therefore, ESC Guidelines no longer support drug interventions to increase HDL-cholesterol [92].

The ESH recommends are careful diagnostic of all parameters of the metabolic vascular syndrome in all patients with hypertension. In these individuals premorbid risk factors of the metabolic vascular syndrome are common inclusive the lipid triad, albuminurea and elevated hsCRP. This clustering of risk factors can be used as a guide to prescription of statins [41].

\section{Anticoagulatory treatment}

Patients with a metabolic vascular syndrome have a complex pathophysiology of cellular and humoral coagulation with activated platelet aggregation, impaired fibrinolysis and elevated factors of the coagulation cascade as major components. This is particularly critical in patients with type 2 diabetes $[94,95]$. Subjects with diabetes have a higher rate of major cardiovascular events but inferior outcomes and effects of intervention after acute coronary syndrome [96]. This can be at least partially explained by harmful alterations in the coagulation associated with the metabolic syndrome. According to this critical weight of atherothrombogenic risk factors randomised trials and meta analysis revealed a greater benefit of anticoagulatory prevention for patients with diabetes and metabolic vascular syndrome.

Acetyl salicylic acid (aspirin) is widely used for secondary prevention in type 2 diabetes. Recently published metaanalysis however reveal no significant impact on mortality while bleeding episodes are significantly increased $[97,98]$. No positive outcome data on primary prevention are available for aspirin and the new platelet aggregation inhibitors such as clopidogrel, prasugrel and ticagrelor. The benefit of low dose aspirin (75-100 mg/d) for secondary prevention is well documented for patients with type 2 diabetes [97]. In the CAPRIE (Clopidogrel versus aspirin in patients at risk of ischaemic events) study clopidogrel $74 \mathrm{mg}$ was significantly more effective in patients with type 2 diabetes compared to aspirin [99]. Incidence of major cardiovascular events (MACE) with clopidogrel was $5.32 \%$, with aspirin $5.83 \%$ (RR $8.7 \%, p=0.043$ ). Benefit of clopidogrel was even higher in patients with peripheral arterial disease. Therefore, the American Diabetes Association (ADA) recommends clopidogrel in very high risk groups with type 2 diabetes. This could be applied in general for type 2 diabetes with metabolic vascular syndrome. New platelet aggregation inhibitors prasugrel and ticogrelor have shown a significantly higher benefit in acute coronary syndrome versus clopidogrel [100], however, large outcome trials in patients with stable atherosclerotic disease are not yet published. Diabetes is an independent risk factor for atrial fibrillation and thrombolic complications. Therefore, risk scores for stroke and systemic embolism result in an indication for anticoagulant therapy with vitamin $\mathrm{K}$ antagonists (cumarins) or direct-acting oral anticoagulants (apixaban, dabigatran, rivaroxaban). No data from controlled prospective trials are available in diabetes comparing old and new anticoagulants.

\section{Conclusion}

In conclusion, a rational diagnostic is needed to elucidate the complex cluster of diseases as basis for an integrated therapy by using synergistic and pleiotropic effects to avoid polypharmacy which is written down in the new German Guideline Metabolic Vascular Syndrome [13].

\section{Future directions}

In the process of globalization with a rapid transition from traditional life habits to westernized life style in developing countries and aging societies in developed countries we will see a further increase in patients with the metabolic vascular syndrome. There is a common soil of malnutrition and inertia which gives a priority to life style intervention for the whole society. The components of the metabolic vascular syndrome and associated risk factors can be used as a simple guide for an individualized medical treatment approach to use synergistic effects of drugs and avoid counterproductive adverse effects.

\section{Acknowledgements}

We will gratefully acknowledge all authors of the Guideline Metabolic Vascular Syndrome and the Chamber of Physicians in Saxony (Sächsische Landes-ärztekammer, Fachkommission Diabetes) for their input.

\section{References}

1. Maranon G (1922) Über Hypertonie und Zuckerkrankheit. Z Inn Med. 43: $169-176$

2. Kylin O (1923) Studien ueber das Hypertonie-HyperglykaemieHyperurikaemiesyndrom. Zentralblatt Inn Med 44: 105-127.

3. VAGUE J (1956) The degree of masculine differentiation of obesities: a factor determining predisposition to diabetes, atherosclerosis, gout, and uric calculous disease. Am J Clin Nutr 4: 20-34.

4. Avagaro P, Nadin C (1967) Association of hyperlipidemia, diabetes mellitus and obesity. Acta Diabetol Let. 4: 572-590.

5. Hanefeld M, Leonhardt W (1981) Das Metabolische Syndrom. Deutsche Gesundheit Wesen 36: 545-552. 
6. Reaven GM (1988) Banting lecture 1988. Role of insulin resistance in human disease. Diabetes 37: 1595-1607.

7. Ferrannini $\mathrm{E}$ (1997) Insulin resistance is central to the burden of diabetes. Diabetes Metab Rev 13: 81-86.

8. Hu G, Qiao Q, Tuomilehto J, Balkau B, Borch-Johnsen K, et al. (2004) Prevalence of the metabolic syndrome and its relation to all-cause and cardiovascular mortality in nondiabetic European men and women. Arch Intern Med 164: 1066-1076.

9. Alberti KG, Zimmet P, Shaw J (2006) Metabolic syndrome--a new worldwide definition. A Consensus Statement from the International Diabetes Federation. Diabet Med 23: 469-480.

10. Expert Panel on Detection, Evaluation, and Treatment of High Blood Cholesterol in Adults (2001) Executive Summary of The Third Report of The National Cholesterol Education Program (NCEP) Expert Panel on Detection, Evaluation, And Treatment of High Blood Cholesterol In Adults (Adult Treatment Panel III). JAMA 285: 2486-2497.

11. Alberti KG, Eckel RH, Grundy SM (2009) Harmonizing the metabolic syndrome: a joint interim statement of the International Diabetes Federation Task Force on Epidemiology and Prevention; National Heart, Lung, and Blood Institute; American Heart Association; World Heart Federation; International Atherosclerosis Society; and International Association for the Study of Obesity. Circulation 120: 1640-1645.

12. Huang JW, Yang CY, Wu HY, Liu KL, Su CT, et al. (2013) Metabolic syndrome and abdominal fat are associated with inflammation, but not with clinical outcomes, in peritoneal dialysis patients. Cardiovasc Diabetol 12: 86

13. Hanefeld M, Rothe U, Fischer S, Scholz GH, Schulze J, et al. (2007) The German Guideline Metabolic Vascular Syndrome. TUD and Academia for Health Saxonia (AGS) (in press).

14. Hanefeld M, Koehler C, Gallo S, et al. (2007) Impact of the individual components of the metabolic syndrome and their different combinations on the prevalence of atherosclerotic vascular disease in type 2 diabetes: the Diabetes in Germany (DIG) study. Cardiovasc Diabetol. 6: 13.

15. Grundy SM (2007) Metabolic syndrome: a multiplex cardiovascular risk factor. J Clin Endocrinol Metab 92: 399-404.

16. Reaven GM (1993) Role of insulin resistance in human disease (syndrome X): an expanded definition. Annu Rev Med 44: 121-131.

17. Cornier MA, Dabelea D, Hernandez TL, Lindstrom RC, Steig AJ, et al. (2008) The metabolic syndrome. Endocr Rev 29: 777-822.

18. Hotamisligil GS (2006) Inflammation and metabolic disorders. Nature 444: 860-867.

19. Bouloumié A, Casteilla L, Lafontan M (2008) Adipose tissue lymphocytes and macrophages in obesity and insulin resistance: makers or markers, and which comes first? Arterioscler Thromb Vasc Biol 28: 1211-1213.

20. Du X, Edelstein D, Obici S, Higham N, Zou MH, et al. (2006) Insulin resistance reduces arterial prostacyclin synthase and eNOS activities by increasing endothelial fatty acid oxidation. J Clin Invest 116: 1071-1080.

21. Rutter MK, Parise H, Benjamin EJ, Levy D, Larson MG, et al. (2003) Impact of glucose intolerance and insulin resistance on cardiac structure and function: sex-related differences in the Framingham Heart Study. Circulation 107: 448-454.

22. Lehman SJ, Massaro JM, Schlett CL, O'Donnell CJ, Hoffmann U, et al. (2010) Peri-aortic fat, cardiovascular disease risk factors, and aortic calcification: the Framingham Heart Study. Atherosclerosis 210: 656-661.

23. Payne GA, Borbouse L, Kumar S (2010) Epicardial perivascular adiposederived leptin exacerbates coronary endothelial dysfunction in metabolic syndrome via a protein kinase C-beta pathway. Arterioscler Thromb Vasc Biol 30: 1711-1717.

24. Meijer RI, Bakker W, Alta CL, Sipkema P, Yudkin JS, et al. (2013) Perivascular adipose tissue control of insulin-induced vasoreactivity in muscle is impaired in $\mathrm{db} / \mathrm{db}$ mice. Diabetes 62: 590-598.

25. Dastani Z, Hivert MF, Timpson N, Perry JR, Yuan X, et al. (2012) Novel loci for adiponectin levels and their influence on type 2 diabetes and metabolic traits: a multi-ethnic meta-analysis of 45,891 individuals. PLoS Genet 8: e1002607.
26. Neeland IJ, Turer AT, Ayers CR, Powell-Wiley TM, Vega GL, et al. (2012) Dysfunctional adiposity and the risk of prediabetes and type 2 diabetes in obese adults. JAMA 308: 1150-1159.

27. Sookoian S, Pirola CJ (2011) Metabolic syndrome: from the genetics to the pathophysiology. Curr Hypertens Rep. 13: 149-57.

28. Fraga MF, Ballestar E, Paz MF et al. (2005) Epigenetic differences arise during the lifetime of monozygotic twins. Proc Natl Acad Sci. U.S.A 102:10604-09.

29. Luyckx VA, Bertram JF, Brenner BM, Fall C, Hoy WE, et al. (2013) Effect of fetal and child health on kidney development and long-term risk of hypertension and kidney disease. Lancet 382: 273-283.

30. Barrès R, Yan J, Egan B, Treebak JT, Rasmussen M, et al. (2012) Acute exercise remodels promoter methylation in human skeletal muscle. Cell Metab 15: 405-411.

31. Burcelin R, Serino M, Chabo C, Blasco-Baque V, Amar J (2011) Gut microbiota and diabetes: from pathogenesis to therapeutic perspective. Acta Diabetol 48: 257-273.

32. Asrih M, Jornayvaz FR (2013) Inflammation as a potential link between nonalcoholic fatty liver disease and insulin resistance. J Endocrinol 218: R25-36.

33. Wall BM (2010) Cardiorenal risk factors. Am J Med Sci 340: 25-29.

34. Tuomilehto J, Lindström J, Eriksson JG, Valle TT, Hämäläinen H, et al. (2001) Prevention of type 2 diabetes mellitus by changes in lifestyle among subjects with impaired glucose tolerance. N Engl J Med 344: 1343-1350.

35. Grundy SM (2012) Pre-diabetes, metabolic syndrome, and cardiovascular risk. J Am Coll Cardiol 59: 635-643.

36. Estruch R, Ros E, Salas-Salvadó J, Covas MI, Corella D, et al. (2013) Primary prevention of cardiovascular disease with a Mediterranean diet. N Engl J Med 368: 1279-1290.

37. Ornish D, Brown SE, Scherwitz LW, Billings JH, Armstrong WT, et al. (1990) Can lifestyle changes reverse coronary heart disease? The Lifestyle Heart Trial. 336: 129-133.

38. Ornish D, Brown SE, Scherwitz LW, Billings JH, Armstrong WT, et al. (1990) Can lifestyle changes reverse coronary heart disease? The Lifestyle Heart Trial. Lancet 336: 129-133.

39. Mente A, de Koning L, Shannon HS, Anand SS (2009) A systematic review of the evidence supporting a causal link between dietary factors and coronary heart disease. Arch Intern Med 169: 659-669.

40. Conroy RM, Pyörälä K, Fitzgerald AP, Sans S, Menotti A, et al. (2003) Estimation of ten-year risk of fatal cardiovascular disease in Europe: the SCORE project. Eur Heart J 24: 987-1003.

41. Mancia G, Fagard R, Narkiewicz K, (2013) 2013 ESH/ESC Guidelines for the management of arterial hypertension: the Task Force for the management of arterial hypertension of the European Society of Hypertension (ESH) and of the European Society of Cardiology (ESC). J Hypertens. 31: 1281-1357.

42. Sharma AM, Pischon T, Hardt S, Kunz I, Luft FC (2001) Hypothesis: Beta-adrenergic receptor blockers and weight gain: A systematic analysis. Hypertension 37: 250-254.

43. Elliott WJ, Meyer PM (2007) Incident diabetes in clinical trials of antihypertensive drugs: a network meta-analysis. Lancet 369: 201-207.

44. Bakris GL, Fonseca V, Katholi RE, McGill JB, Messerli FH, et al. (2004) Metabolic effects of carvedilol vs metoprolol in patients with type 2 diabetes mellitus and hypertension: a randomized controlled trial. JAMA 292: 2227-2236.

45. Celik T, Iyisoy A, Kursaklioglu H, Kardesoglu E, Kilic S, et al. (2006) Comparative effects of nebivolol and metoprolol on oxidative stress, insulin resistance, plasma adiponectin and soluble P-selectin levels in hypertensive patients. J Hypertens 24: 591-596.

46. Jamerson K, Weber MA, Bakris GL (2008) Benazepril plus amlodipine or hydrochlorothiazide for hypertension in high-risk patients. N Engl J Med 359:2417-2428. 
47. Shafi T, Appel LJ, Miller ER 3rd, Klag MJ, Parekh RS (2008) Changes in serum potassium mediate thiazide-induced diabetes. Hypertension 52: 1022-1029.

48. Stears AJ, Woods SH, Watts MM, Burton TJ, Graggaber J, et al. (2012) A double-blind, placebo-controlled, crossover trial comparing the effects of amiloride and hydrochlorothiazide on glucose tolerance in patients with essential hypertension. Hypertension 59: 934-942.

49. Verdecchia P, Reboldi G, Angeli F, Gattobigio R, Bentivoglio M, et al. (2005) Angiotensin-converting enzyme inhibitors and calcium channel blockers for coronary heart disease and stroke prevention. Hypertension 46: 386-392.

50. Bakris GL, Sarafidis PA, Weir MR (2010) Renal outcomes with different fixed-dose combination therapies in patients with hypertension at high risk for cardiovascular events (ACCOMPLISH): a prespecified secondary analysis of a randomised controlled trial. Lancet 375: 1173-1181.

51. Yusuf S, Teo KK, Pogue J (2008) Telmisartan, ramipril, or both in patients at high risk for vascular events. N Engl J Med 358:1547-59.

52. Yusuf S, Sleight P, Pogue J (2000) Effects of an angiotensin-convertingenzyme inhibitor, ramipril, on cardiovascular events in high-risk patients. The Heart Outcomes Prevention Evaluation Study Investigators. N Engl J Med 342: 145-153.

53. DREAM Trial Investigators, Bosch J, Yusuf S, Gerstein HC, Pogue J, et al. (2006) Effect of ramipril on the incidence of diabetes. N Engl J Med 355 1551-1562.

54. NAVIGATOR Study Group, McMurray JJ, Holman RR, Haffner SM, Bethel MA, et al. (2010) Effect of valsartan on the incidence of diabetes and cardiovascular events. N Engl J Med 362: 1477-1490.

55. Knowler WC, Barrett-Connor E, Fowler SE, et al. (2002) Reduction in the incidence of type 2 diabetes with lifestyle intervention or metformin. $\mathrm{N}$ Engl J Med 346: 393-403.

56. Chiasson JL, Josse RG, Gomis R, Hanefeld M, Karasik A, et al. (2002) Acarbose for prevention of type 2 diabetes mellitus: the STOP-NIDDM randomised trial. Lancet 359: 2072-2077.

57. DREAM On (Diabetes Reduction Assessment with Ramipril and Rosiglitazone Medication Ongoing Follow-up) Investigators, Gerstein HC, Mohan V, Avezum A, Bergenstal RM, et al. (2011) Long-term effect of rosiglitazone and/or ramipril on the incidence of diabetes. Diabetologia 54: 487-495.

58. Defronzo RA, Tripathy D, Schwenke DC, Banerji M, Bray GA, et al. (2013) Prevention of diabetes with pioglitazone in ACT NOW physiologic correlates. Diabetes 62: 3920-3926.

59. Zinman B, Harris SB, Neuman J, Gerstein HC, Retnakaran RR, et al. (2010) Low-dose combination therapy with rosiglitazone and metformin to prevent type 2 diabetes mellitus (CANOE trial): a double-blind randomised controlled study. Lancet 376: 103-111.

60. Hanefeld M, Marx N, Pfützner A, Baurecht W, Lübben G, et al. (2007) Anti-inflammatory effects of pioglitazone and/or simvastatin in high cardiovascular risk patients with elevated high sensitivity C-reactive protein: the PIOSTAT Study. J Am Coll Cardiol 49: 290-297.

61. Pistrosch F, Passauer J, Herbrig K, Schwanebeck U, Gross P, et al. (2012) Effect of thiazolidinedione treatment on proteinuria and renal hemodynamic in type 2 diabetic patients with overt nephropathy. Horm Metab Res 44: 914-918.

62. Pistrosch F, Passauer J, Fischer S, Fuecker K, Hanefeld M, et al. (2004) In type 2 diabetes, rosiglitazone therapy for insulin resistance ameliorates endothelial dysfunction independent of glucose control. Diabetes Care 27: 484-490.

63. Kung J, Henry RR (2012) Thiazolidinedione safety. Expert Opin Drug Saf 11: 565-579.

64. Torgerson JS, Hauptman J, Boldrin MN, Sjöström L (2004) XENical in the prevention of diabetes in obese subjects (XENDOS) study: a randomized study of orlistat as an adjunct to lifestyle changes for the prevention of type 2 diabetes in obese patients. Diabetes Care 27: 155-161.

65. Diabetes Prevention Program Outcomes Study Research Group, Orchard TJ, Temprosa M, Barrett-Connor E, Fowler SE, et al. (2013) Long-term effects of the Diabetes Prevention Program interventions on cardiovascular risk factors: a report from the DPP Outcomes Study. Diabet Med 30: 46-55.

66. Charles MA, Eschwège E, Grandmottet $\mathrm{P}$, Isnard $\mathrm{F}$, Cohen JM, et al. (2000) Treatment with metformin of non-diabetic men with hypertension, hypertriglyceridaemia and central fat distribution: the BIGPRO 1.2 trial. Diabetes Metab Res Rev 16: 2-7.

67. Chiasson JL, Josse RG, Gomis R, Hanefeld M, Karasik A, et al. (2003) Acarbose treatment and the risk of cardiovascular disease and hypertension in patients with impaired glucose tolerance: the STOPNIDDM trial. JAMA 290: 486-494.

68. Rudofsky G Jr, Reismann P, Schiekofer S, Petrov D, von Eynatten M, et al. (2004) Reduction of postprandial hyperglycemia in patients with type 2 diabetes reduces NF-kappaB activation in PBMCs. Horm Metab Res 36: 630-638.

69. Hanefeld M, Cagatay M, Petrowitsch T, Neuser D, Petzinna D, et al. (2004) Acarbose reduces the risk for myocardial infarction in type 2 diabetic patients: meta-analysis of seven long-term studies. Eur Heart J 25: $10-16$.

70. Hanefeld M, Pistrosch F, Koehler C, Chiasson JL (2012) Conversion of IGT to type 2 diabetes mellitus is associated with incident cases of hypertension: a post-hoc analysis of the STOP-NIDDM trial. J Hypertens 30: 1440-1443.

71. Hanefeld M, Karasik A, Koehler C, Westermeier T, Chiasson JL (2009) Metabolic syndrome and its single traits as risk factors for diabetes in people with impaired glucose tolerance: the STOP-NIDDM trial. Diab Vasc Dis Res 6: 32-37.

72. ORIGIN Trial Investigators, Gerstein HC, Bosch J, Dagenais GR, Díaz R, et al. (2012) Basal insulin and cardiovascular and other outcomes in dysglycemia. N Engl J Med 367: 319-328.

73. Terán-García M, Bouchard C (2007) Genetics of the metabolic syndrome. Appl Physiol Nutr Metab 32: 89-114.

74. Taylor F, Huffman MD, Macedo AF, Moore TH, Burke M, et al. (2013) Statins for the primary prevention of cardiovascular disease. Cochrane Database Syst Rev 1: CD004816.

75. Tonelli M, Lloyd A, Clement F, Conly J, Husereau D, et al. (2011) Efficacy of statins for primary prevention in people at low cardiovascular risk: a meta-analysis. CMAJ 183: E1189-1202.

76. Yusuf S, Islam S, Chow CK, Rangarajan S, Dagenais G, et al. (2011) Use of secondary prevention drugs for cardiovascular disease in the community in high-income, middle-income, and low-income countries (the PURE Study): a prospective epidemiological survey. Lancet 378: 1231-1243.

77. Spector R, Snapinn SM (2011) Statins for secondary prevention of cardiovascular disease: the right dose. Pharmacology 87: 63-69.

78. Tonkin AM, Chen L (2010) Effects of combination lipid therapy in the management of patients with type 2 diabetes mellitus in the Action to Control Cardiovascular Risk in Diabetes (ACCORD) trial. Circulation 122: 850-852.

79. Burgess DC, Hunt D, Li L, Zannino D, Williamson E, et al. (2010) Incidence and predictors of silent myocardial infarction in type 2 diabetes and the effect of fenofibrate: an analysis from the Fenofibrate Intervention and Event Lowering in Diabetes (FIELD) study. Eur Heart J 31: 92-99.

80. Cholesterol Treatment Trialistsa ${ }^{\mathrm{ma}}$ (CTT) Collaboration, Baigent C, Blackwell L, Emberson J, Holland LE, et al. (2010) Efficacy and safety of more intensive lowering of LDL cholesterol: a meta-analysis of data from 170,000 participants in 26 randomised trials. Lancet 376: 1670-1681.

81. Ridker PM, Danielson E, Fonseca FA.(2008) Rosuvastatin to prevent vascular events in men and women with elevated C-reactive protein. N.Engl.J.Med 359:2195-207.

82. Ooi EM, Watts GF, Chan DC, Chen MM, Nestel PJ, et al. (2008) Dosedependent effect of rosuvastatin on VLDL-apolipoprotein C-III kinetics in the metabolic syndrome. Diabetes Care 31: 1656-1661.

83. Rosenson RS, Otvos JD, Hsia J (2009) Effects of rosuvastatin and atorvastatin on LDL and HDL particle concentrations in patients with 
Citation: Hanefeld M, Pistrosch F, Schulze J, Rothe U (2014) The Metabolic Syndrome and Cardiovascular Diseases: An Update of Medical Treatment. J Metabolic Synd 3: 160. doi:10.4172/2167-0943.1000160

Page 8 of 8

metabolic syndrome: a randomized, double-blind, controlled study. Diabetes Care 32: 1087-1091.

84. Preiss D, Seshasai SR, Welsh P, Murphy SA, Ho JE, et al. (2011) Risk of incident diabetes with intensive-dose compared with moderate-dose statin therapy: a meta-analysis. JAMA 305: 2556-2564.

85. Strazzullo P, Kerry SM, Barbato A, Versiero M, D'Elia L, et al. (2007) Do statins reduce blood pressure?: a meta-analysis of randomized, controlled trials. Hypertension 49: 792-798.

86. Tenkanen L, Mänttäri $\mathrm{M}$, Kovanen $\mathrm{PT}$, Virkkunen $\mathrm{H}$, Manninen V (2006) Gemfibrozil in the treatment of dyslipidemia: an 18-year mortality follow-up of the Helsinki Heart Study. Arch Intern Med 166: 743-748.

87. Frick MH, Elo O, Haapa K, Heinonen OP, Heinsalmi P, et al. (1987) Helsinki Heart Study: primary-prevention trial with gemfibrozil in middle-aged men with dyslipidemia. Safety of treatment, changes in risk factors, and incidence of coronary heart disease. N Engl J Med 317: 1237-1245.

88. Rubins HB, Robins SJ, Collins D (1999) Gemfibrozil for the secondary prevention of coronary heart disease in men with low levels of highdensity lipoprotein cholesterol. Veterans Affairs High-Density Lipoprotein Cholesterol Intervention Trial Study Group. N Engl J Med 341: 410-418.

89. Davidson MH, Armani A, McKenney JM, Jacobson TA (2007) Safety considerations with fibrate therapy. Am J Cardiol 99: 3C-18C.

90. AIM-HIGH Investigators, Boden WE, Probstfield JL, Anderson T, Chaitman BR, et al. (2011) Niacin in patients with low HDL cholesterol levels receiving intensive statin therapy. N Engl J Med 365: 2255-2267.

91. Schwartz GG, Olsson AG, Abt M, Ballantyne CM, Barter PJ, et al. (2012) Effects of dalcetrapib in patients with a recent acute coronary syndrome. N Engl J Med 367: 2089-2099.
92. Barter PJ, Caulfield M, Eriksson M, Grundy SM, Kastelein JJ, et al. (2007) Effects of torcetrapib in patients at high risk for coronary events. N Engl J Med 357: 2109-2122.

93. Catapano AL, Reiner Z, De Backer G, Graham I, Taskinen MR, et al. (2011) ESC/EAS Guidelines for the management of dyslipidaemias The Task Force for the management of dyslipidaemias of the European Society of Cardiology (ESC) and the European Atherosclerosis Society (EAS). Atherosclerosis 217: 3-46.

94. Gawaz M, Langer H, May AE (2005) Platelets in inflammation and atherogenesis. J Clin Invest 115: 3378-3384.

95. Randriamboavonjy V, Fleming I (2012) Platelet function and signaling in diabetes mellitus. Curr Vasc Pharmacol 10: 532-538.

96. Donahoe SM, Stewart GC, McCabe CH, Mohanavelu S, Murphy SA, et al. (2007) Diabetes and mortality following acute coronary syndromes. JAMA 298: 765-775.

97. Antithrombotic Trialists' (ATT) Collaboration, Baigent C, Blackwell L, Collins R, Emberson J, et al. (2009) Aspirin in the primary and secondary prevention of vascular disease: collaborative meta-analysis of individual participant data from randomised trials. Lancet 373: 1849-1860.

98. Seshasai SR, Wijesuriya S, Sivakumaran R, Nethercott S, Erqou S, et al. (2012) Effect of aspirin on vascular and nonvascular outcomes: metaanalysis of randomized controlled trials. Arch Intern Med 172: 209-216.

99. Bhatt DL, Marso SP, Hirsch AT, Ringleb PA, Hacke W, et al. (2002) Amplified benefit of clopidogrel versus aspirin in patients with diabetes mellitus. Am J Cardiol 90: 625-628.

100. Wallentin L, Becker RC, Budaj A, Cannon CP, Emanuelsson H, et al. (2009) Ticagrelor versus clopidogrel in patients with acute coronary syndromes. N Engl J Med 361: 1045-1057. 